Case Reports in
Gastroenterology
Case Rep Gastroenterol 2021;15:123-130

DOI: $10.1159 / 000512399$

Published online: February 3, 2021

(c) 2021 The Author(s)

Published by S. Karger AG, Base www.karger.com/crg

This article is licensed under the Creative Commons Attribution-NonCommercial 4.0 International License (CC BY-NC) (http://www.karger.com/Services/OpenAccessLicense). Usage and distribution for commercial purposes requires written permission.

\title{
Large Fundic Gland Polyp Associated with Long-Term Proton Pump Inhibitor Administration Mimicking Gastric-Type Neoplasm
}

\author{
Yorinari Ochiai $^{\mathrm{a}}$ Daisuke Kikuchi $^{\mathrm{a}}$ Shinji Ito ${ }^{\mathrm{b}}$ Yutaka Takazawa $^{\mathrm{b}}$ \\ Shu Hoteya ${ }^{a}$ \\ aDepartment of Gastroenterology, Toranomon Hospital, Tokyo, Japan; 'bepartment of \\ Pathology, Toranomon Hospital, Tokyo, Japan
}

\section{Keywords}

Proton pump inhibitor - Endoscopic submucosal dissection - Fundic gland polyp - Endoscopy . Narrow-band imaging · Gastric-type neoplasm

\begin{abstract}
A 57-year-old man with a 10-year history of proton pump inhibitor (PPI) use presented with multiple fundic gland polyps (FGPs) including one $>20 \mathrm{~mm}$, whitish, semi-pedunculated polyp. Black spots and cobblestone-like mucosa were also observed in the stomach upon endoscopy; therefore, the lesion was considered to result from long-term PPI administration. Endoscopically, we diagnosed this polyp as a neoplastic lesion with gastric phenotype rather than a nonneoplastic lesion. Biopsy revealed an atypical glandular lesion that was indeterminate for neoplasia; therefore, we performed en bloc resection via endoscopic submucosal dissection (ESD) of the $22 \times 22 \times 10 \mathrm{~mm}$-sized polyp. Histologically, the polyp was composed of hyperplastic foveolar epithelia in the upper half of the mucosa and hyperplastic fundic glands in the lower half of the mucosa, with luminal dilatation and parietal cell protrusion. The pathological diagnosis for this ESD specimen was FGP associated with PPI administration. We herein describe this rare case of a large FGP in Helicobacter pylori-uninfected gastric mucosa associated with long-term PPI administration, which was mimicking gastric-type neoplasm and resected by endoscopy.




\section{Case Reports in Gastroenterology}

Case Rep Gastroenterol 2021;15:123-130

DOI: $10.1159 / 000512399$

(c) 2021 The Author(s). Published by S. Karger AG, Basel www.karger.com/crg

Ochiai et al.: Large Fundic Gland Polyp Mimicking Gastric-Type Neoplasm

\section{Introduction}

Proton pump inhibitors (PPIs) are considered relatively safe drugs and are widely used. However, after long-term PPI administration, the gastric mucosa may develop fundic gland polyps (FGPs), black spots, and cobblestone-like mucosa $[1,2]$. Pathologically, hyperplasia of parietal cells and parietal cell protrusion into the lumen are typical findings [3]. Although hypoacidity and hypergastrinemia increase the risk of gastric cancer in the corpus and fundus $[4,5]$, the relationship between long-term PPI administration and tumor development remains unclear. Herein, we report the rare case of a $22 \times 22 \times 10 \mathrm{~mm}$ FGP in Helicobacter pylori (H. pylori)-uninfected gastric mucosa associated with long-term PPI administration that was mimicking gastric-type neoplasm and resected via endoscopy.

\section{Case Report}

A 57-year-old Japanese man had been taking lansoprazole for at least 10 years for gastroesophageal reflux. He had no new symptoms and no major medical history. Upper gastrointestinal endoscopy conducted for routine screening revealed multiple hydrops-like FGPs in the background mucosa without atrophy. A semi-pedunculated polyp $>20 \mathrm{~mm}$ in size with black spots on the surface was found on the posterior wall of the greater curvature of the stomach (Fig. 1). In narrow-band imaging magnifying endoscopy (NBI-ME), the microsurface pattern showed circular gland duct openings in some areas, though the pattern was obscure in parts of the lesion. The microvascular pattern showed an enlarged blood vessel that ran laterally on the surface in most of the lesion. In addition, microvessels presenting tortuosity and slight dilatation were recognized in the parts where the microsurface pattern was obscure, although no caliber change or shape variations were noted (Fig. 2). Based on these endoscopic findings, we diagnosed this polyp as a neoplastic lesion with gastric phenotype rather than a non-neoplastic lesion. Biopsy results confirmed an atypical glandular lesion that was indeterminate for neoplasia. Therefore, we performed en bloc resection by endoscopic submucosal dissection (ESD) using a dual knife (Olympus Co., Ltd., Tokyo, Japan). Macroscopically, the lesion was a semi-pedunculated polyp that was $22 \times 22 \times 10 \mathrm{~mm}$ in size (Fig. 3). Histologically, the polyp was composed of hyperplastic foveolar epithelia in the upper half of the mucosa and hyperplastic fundic glands in the lower half of the mucosa, with luminal dilatation and parietal cell protrusion, which is typical of PPI-related FGPs (Fig. 4). No structural or cytological atypia was observed in the lesion and it was pathologically diagnosed as an FGP associated with PPI administration.

The patient had no history of $H$. pylori eradication, and $H$. pylori antibody and stool $H$. pylori antigen were both negative, which suggests no prior $H$. pylori infection of the gastric mucosa. As such, this large FGP associated with PPI administration was considered to have developed in H. pylori-uninfected gastric mucosa.

\section{Discussion}

In this case, the patient presented with a large FGP which was determined to result from extended PPI use. FGPs may occur sporadically or in association with syndromes such as familial adenomatous polyposis (FAP). Sporadic FGPs have been reported in $0.8-1.9 \%$ of

\section{Karger'=}




\section{Case Reports in Gastroenterology}

Case Rep Gastroenterol 2021;15:123-130

DOI: $10.1159 / 000512399$

(c) 2021 The Author(s). Published by S. Karger AG, Basel www.karger.com/crg

Ochiai et al.: Large Fundic Gland Polyp Mimicking Gastric-Type Neoplasm

patients undergoing esophagogastroduodenoscopy, and their occurrence has been associated with prolonged use of PPIs [6]. In our case, there was no clinical or colonoscopic evidence of FAP. Therefore, the lesion in our case was sporadic. In addition, the ESD specimen in this case demonstrated fundic gland hyperplasia and parietal cell protrusion, which have been widely observed in patients with long-term PPI administration. Therefore, our case was considered a PPI-related lesion. A report from Japan [7] indicated that $13.6 \%$ of patients developed new FGPs after rabeprazole administration for 104 weeks. These developed mainly in the corpus and were $<5 \mathrm{~mm}$. In this case, the $22 \times 22 \times 10 \mathrm{~mm}$ lesion was much larger than a common FGP. Although the mechanism of such large, sporadic FGP growth over long-term observation is unknown, our case suggests that FGPs could enlarge with long-term administration of PPI.

Endoscopic changes after long-term PPI administration include FGPs, black spots, and cobblestone-like mucosa; however, there are few detailed reports about PPI-related polyps, and characteristic findings in NBI-ME have not been well investigated. In our case, we found two patterns via NBI-ME: one pattern that was consistent with an FGP and one pattern that demonstrated microsurface and microvascular irregularities. We were unsure whether this lesion was neoplastic because the microsurface pattern did not present irregularities typical of neoplasia and the microvascular pattern did not meet all four signs of neoplasia (dilatation, tortuosity, caliber change, and various shapes). These findings might have been caused by inflammation due to polyp size or location in the stomach. As mentioned above, it is sometimes difficult to endoscopically determine whether a large lesion is neoplastic or non-neoplastic.

In the present case, we selected ESD as the treatment strategy because this large semipedunculated polyp was suspected to be neoplastic based on endoscopic findings and the preoperative biopsy could not rule out neoplasm either. There are few reports of treatment for PPI-related gastric polyps; however, we found one report of endoscopic mucosal resection for a 10-mm FGP with low-grade dysplasia [8].

It is also sometimes difficult to pathologically differentiate large FGPs from gastric-type neoplasia by biopsy specimen because FGPs associated with PPI use might show slight atypia or dysplastic changes. Previous literature reported that FGPs were detected in $88 \%$ of FAP patients and were dysplastic in $41 \%$ of patients [9]. In contrast, low-grade epithelial dysplasia has been reported in sporadic FGPs; however, its prevalence is said to be extremely low (approximately 1\%) [10]. One paper reported that an FGP with dysplasia did not transform into invasive cancer although the patient underwent 14 years of PPI therapy [11]. Follow-up data from 26 cases of sporadic FGP with low-grade dysplasia also suggested that these lesions might be indolent in nature [10]. The malignant potential of PPI-related FGPs remains to be elucidated.

In conclusion, we herein report a rare case of a large FGP in H. pylori-uninfected gastric mucosa associated with long-term PPI administration, which was mimicking gastric-type neoplasm and resected by endoscopy.

\section{Statements of Ethics}

The patient provided written informed consent for publication of data and images.

\section{Karger' $=$}




\section{Case Reports in Gastroenterology}

\section{Conflict of Interest Statement}

The authors declare that they have no conflicts of interest to disclose.

\section{Funding Sources}

None declared.

\section{Author Contributions}

Y. Ochiai wrote the draft of the research study. Y. Ochiai, D. Kikuchi, and S. Hoteya conducted the data acquisition and revised the draft. S. Ito and Y. Takazawa analyzed the pathological findings. S. Hoteya supervised this case report.

\section{References}

1 Jalving M, Koornstra JJ, Wesseling J, Boezen HM, DE Jong S, Kleibeuker JH. Increased risk of fundic gland polyps during long-term proton pump inhibitor therapy. Aliment Pharmacol Ther. 2006 Nov;24(9):1341-8.

2 Hatano Y, Haruma K, Ayaki M, Kamada T, Ohtani H, Murao T, et al. Black Spot, a Novel Gastric Finding Potentially Induced by Proton Pump Inhibitors. Intern Med. 2016;55(21):3079-84.

3 Parfitt JR, Driman DK. Pathological effects of drugs on the gastrointestinal tract: a review. Hum Pathol. 2007 Apr;38(4):527-36.

4 Fossmark R, Martinsen TC, Waldum HL. Adverse Effects of Proton Pump Inhibitors - Evidence and Plausibility. Int J Mol Sci. 2019 Oct;20(20):E5203.

5 Fukuda M, Ishigaki H, Sugimoto M, Mukaisho KI, Matsubara A, Ishida H, et al. Histological analysis of fundic gland polyps secondary to PPI therapy. Histopathology. 2019 Oct;75(4):537-45.

6 Kinoshita Y, Tojo M, Yano T, Kitajima N, Itoh T, Nishiyama K, et al. Incidence of fundic gland polyps in patients without familial adenomatous polyposis. Gastrointest Endosc. 1993 Mar-Apr;39(2):161-3.

7 Hongo M, Fujimoto K; Gastric Polyps Study Group. Incidence and risk factor of fundic gland polyp and hyperplastic polyp in long-term proton pump inhibitor therapy: a prospective study in Japan. J Gastroenterol. 2010 Jun;45(6):618-24.

8 Shibukawa N, Wakahara Y, Ouchi S, Wakamatsu S, Kaneko A. Synchronous Three Gastric Fundic Gland Polyps with Low-grade Dysplasia Treated with Endoscopic Mucosal Resection after Being Diagnosed to Be Tubular Adenocarcinoma Based on a Biopsy Specimen. Intern Med. 2019 Jul;58(13):1871-5.

9 Bianchi LK, Burke CA, Bennett AE, Lopez R, Hasson H, Church JM. Fundic gland polyp dysplasia is common in familial adenomatous polyposis. Clin Gastroenterol Hepatol. 2008 Feb;6(2):180-5.

10 Levy MD, Bhattacharya B. Sporadic Fundic Gland Polyps With Low-Grade Dysplasia: A Large Case Series Evaluating Pathologic and Immunohistochemical Findings and Clinical Behavior. Am J Clin Pathol. 2015 Oct;144(4):592-600.

11 Fukuda M, Ishigaki H, Ban H, Sugimoto M, Tanaka E, Yonemaru J, et al. No transformation of a fundic gland polyp with dysplasia into invasive carcinoma after 14 years of follow-up in a proton pump inhibitor-treated patient: A case report. Pathol Int. 2018 Dec;68(12):706-11. 
Case Reports in Gastroenterology
Case Rep Gastroenterol 2021;15:123-130

DOI: $10.1159 / 000512399$

(C) 2021 The Author(s). Published by S. Karger AG, Basel www.karger.com/crg

Ochiai et al.: Large Fundic Gland Polyp Mimicking Gastric-Type Neoplasm
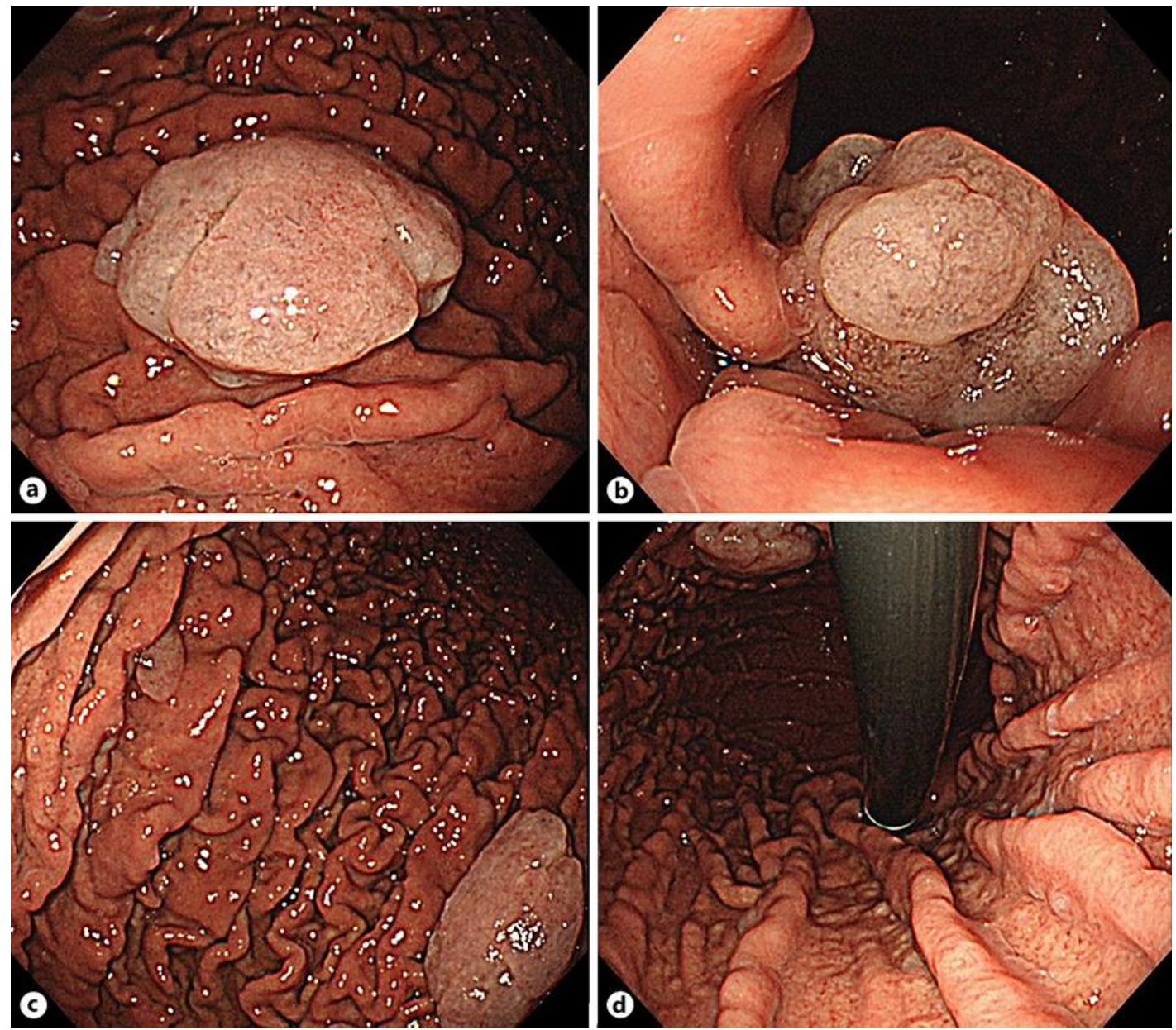

Fig. 1. White-light images of the lesion and background of the stomach. a, b A whitish elevated polyp with black spots on the surface. Hydrops-like whitish polyps (c) and cobblestone-like mucosa (d) are seen in the background. 


\section{Case Reports in Gastroenterology}
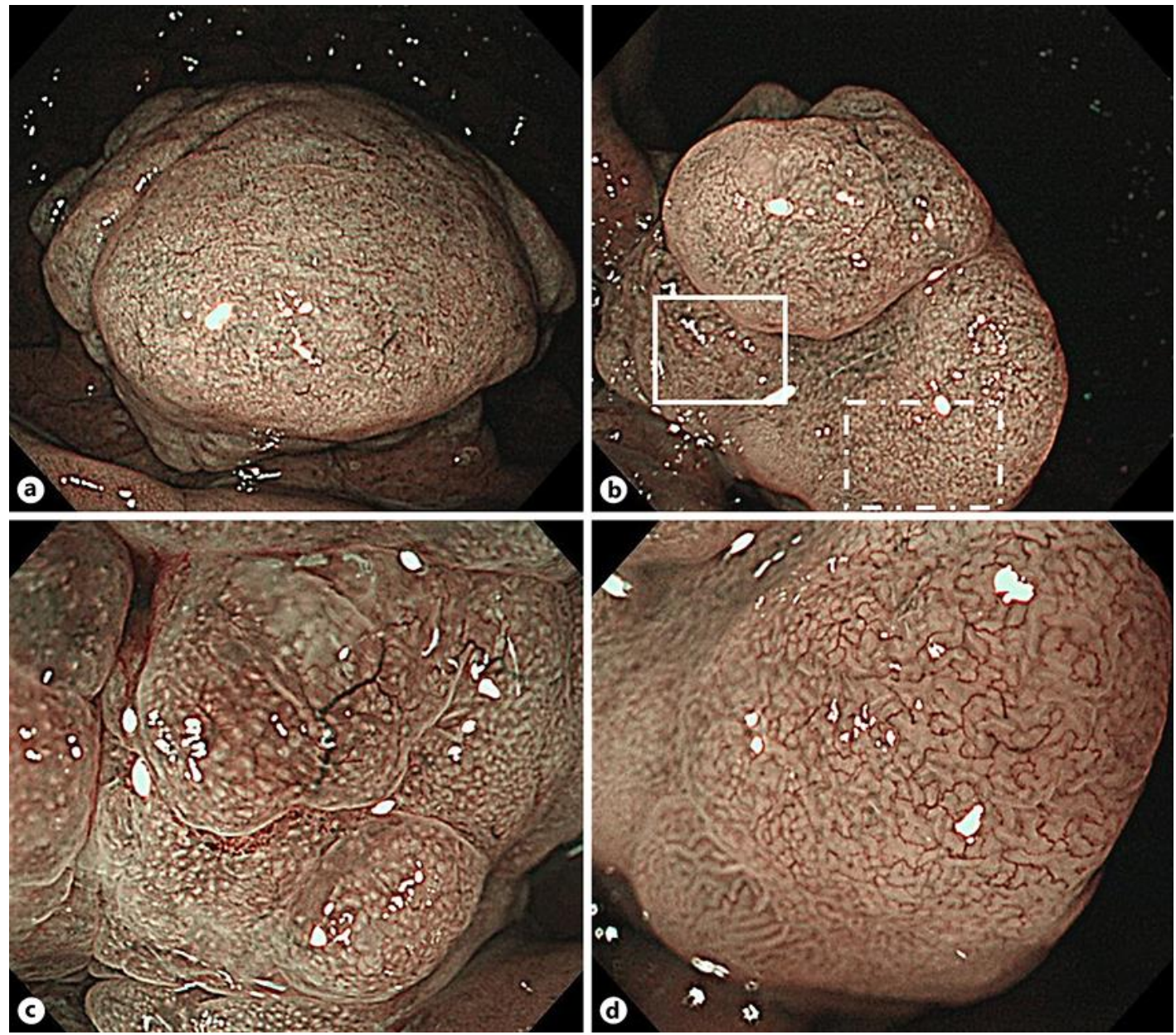

Fig. 2. Images of the lesion by NBI-ME. $\mathbf{a}$ The entire lesion by unmagnified NBI-ME. $\mathbf{b}$ The anal side of the lesion in retroflex observation by unmagnified NBI-ME. c Magnified NBI-ME view of the area framed by the white solid box in b. d Magnified NBI-ME view of the area framed by the white dashed box in $\mathbf{b}$. NBI-ME, narrow-band imaging magnifying endoscopy. 
Case Reports in Gastroenterology
Case Rep Gastroenterol 2021;15:123-130

DOI: $10.1159 / 000512399$

(c) 2021 The Author(s). Published by S. Karger AG, Basel www.karger.com/crg

Ochiai et al.: Large Fundic Gland Polyp Mimicking Gastric-Type Neoplasm
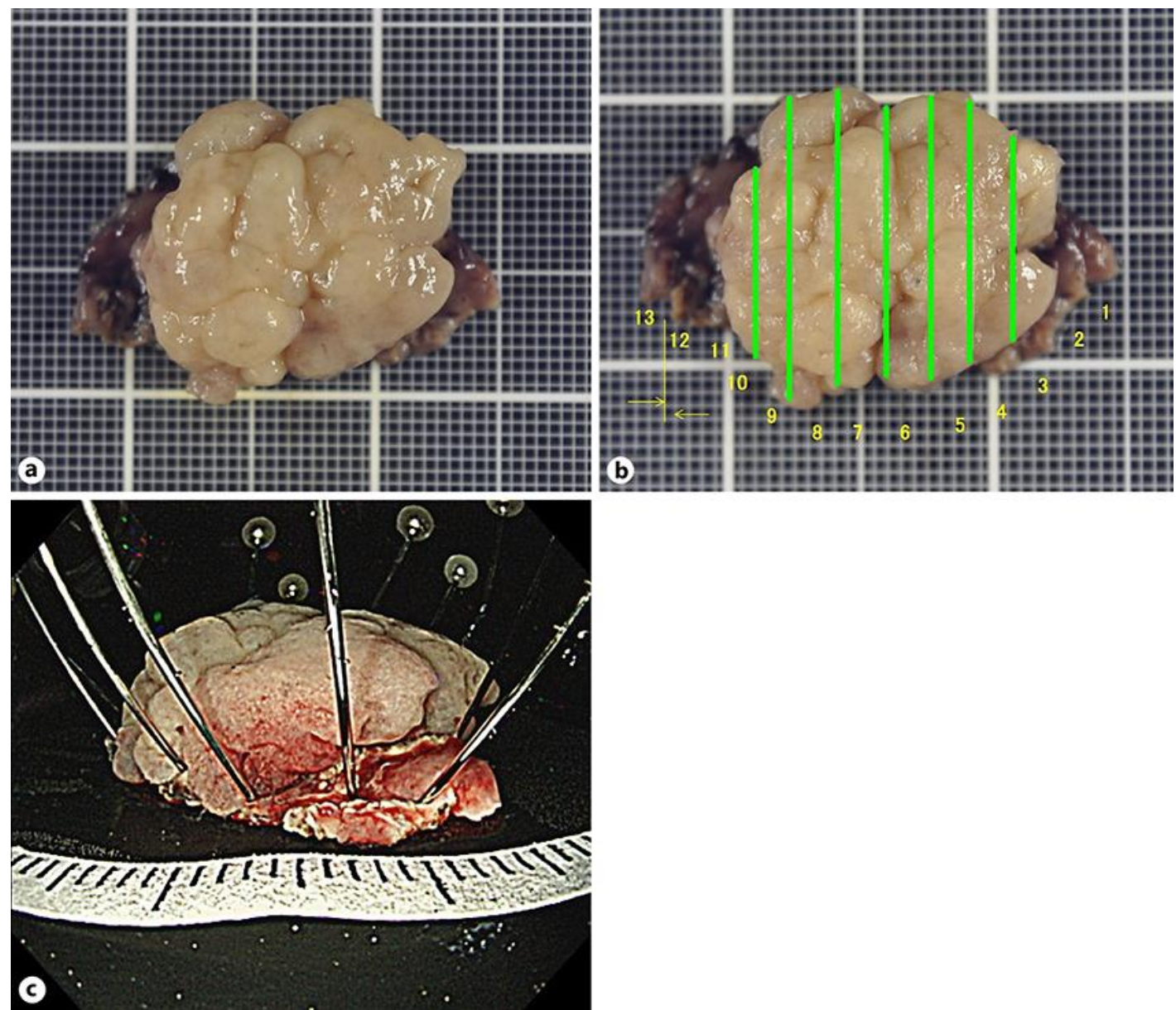

Fig. 3. Specimen resected by endoscopic submucosal dissection. a The resected lesion. $\mathbf{b}$ Green lines show the area of the lesion. c Side view of the resected lesion. 
Case Reports in Gastroenterology
Case Rep Gastroenterol 2021;15:123-130

DOI: 10.1159/000512399

๑ 2021 The Author(s). Published by S. Karger AG, Basel www.karger.com/crg

Ochiai et al.: Large Fundic Gland Polyp Mimicking Gastric-Type Neoplasm

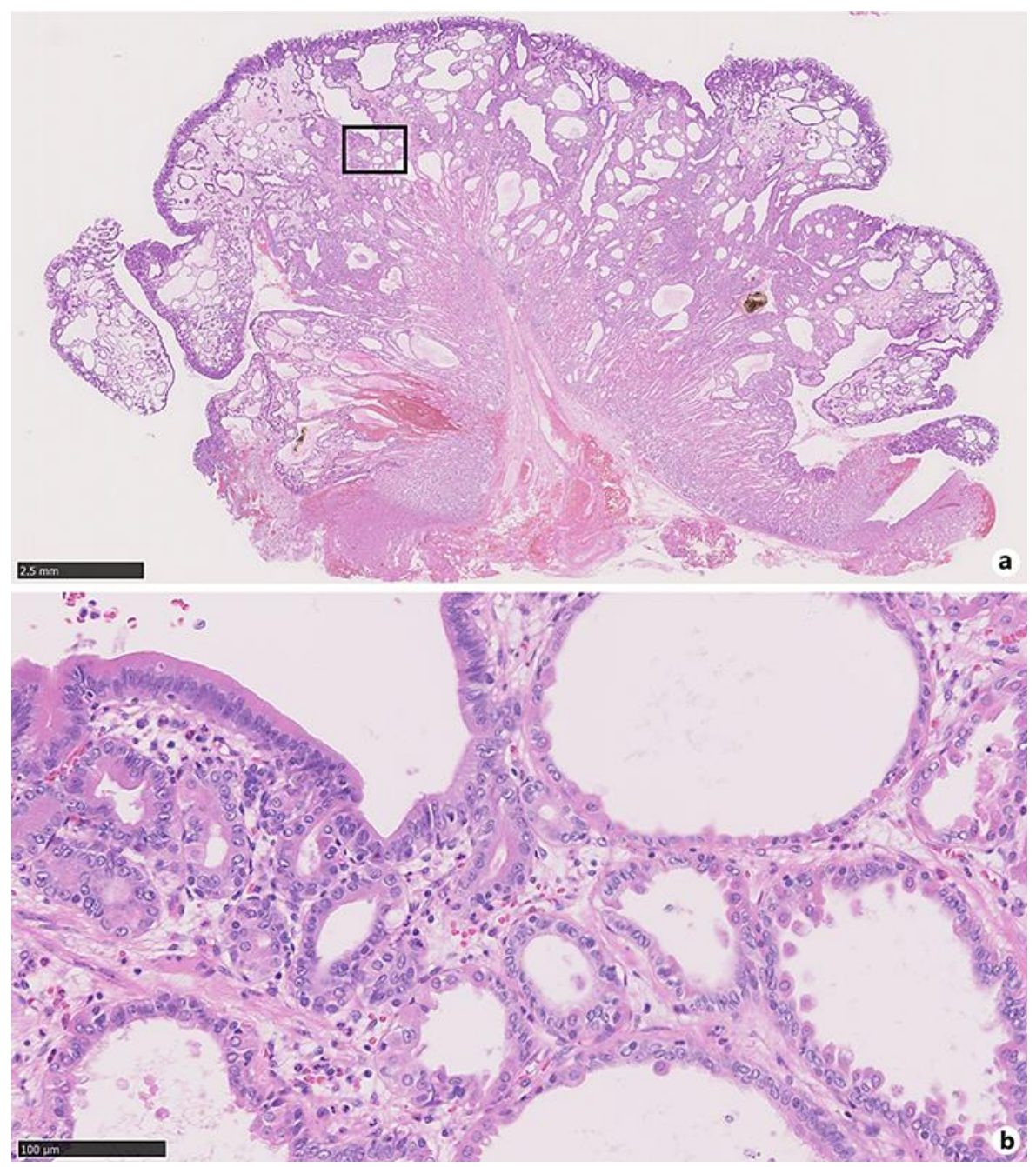

Fig. 4. Histological images of the lesion (hematoxylin and eosin staining). a The section of the lesion showing polypoid proliferation with cystic glands and mild foveolar hyperplasia. $\mathbf{b}$ Higher magnification of the area framed by the black solid box in a showing hyperplastic changes and parietal cell protrusion. 